\title{
Pitfalls in the Assessment in Distance Learning
}

\author{
Nita Thalia
}

Thalia Global Pro

\begin{abstract}
The assessment of learning and the a ssessment for learning are considered as an integral part of learning process. They provide information to improve the educational instructions and to boost the students' performances. It is a critical a spect of teaching and learning process and it requires teachers and learners to be prepared for the whole situation. The assessment is a complex process and its implementation poses many challenges to teachers. Online tools and learning management systems (LMS) help to overcome most of these challenges. During the COVID 19 pandemic, almost all schools and universities switched to distance learning and teachers had to change their way of teaching. However, many problems arose from this situation; The "new" teaching mode raised many discussions and needs to be analyzed thoroughly. In this paper, we discuss the usage of distance learning resources during the lock-down and the issues it generated. We focus on the assessment process in the circumstances of COVID-19. For the purpose of his study, future teachers were surveyed after their experience with distance teaching. It seems that platforms providing interactive assessment and those allowing automatic evaluation of learners are more required than others.
\end{abstract}

Keywords

Distance learning; learning management system (LMS); Assessment; COVID-19

\section{Introduction}

Assessment

Assessment is an essential part of learning. It is intrinsic to any educational process and it is considered as the most important influentialfactor in any learning process. It aims to collect information on what has been retained and what has been understood from the courses administered in class. Actually, assessment requires the use of accurate methods and measures to measure a student's performance relative to the learning objectives.

Assessment has three functions: diagnostic, formative, and summative. In all its forms, assessment attracts the focus of many stakeholders, including policymakers, teachers, students and parents. Each one of them has his own expectations and perspectives. Its implementation in any educational curriculum is highly compulsory to support the students' learning. It leads to make inferences about students' mastery of key learning outcomes and gives hints to improve the educational programs or the teaching strategies. It plays such an essential role in providing evidence, which is used in a systematic way to make decisions and to determine how well students' learning matches expectations.

Certainly, the assessment is essential in every teaching process and has powerful impact on learning outcomes. However, it remains likely the most complex process and stimulates a critical reflection from teachers and educationalauthorities. 
The process of assessment is the concern of several parties. It involves primarily the teacher and the student as main actors. It concerns mainly the student since it allows him to determine his instructional level and to monitor his progress. He/she needs to know his/her strengths and potentials as well as his/her limitations and weaknesses. The teacher needs to monitor progress. He/she needs to make adjustments and to develop his/her professional practices related to both teaching strategies and assessment practices. He/she has to regulate or co-regulate the learning with the learners based on the results and the analyses of assessment. Teachers ha ve also a duty toward an outer environment. He/she also needs to inform the educational authorities. Nationwide assessments are orga nized at the end of each year or unit to assess the general learner's instructionallevel and to assess the teacher's performance. The assessment is also subject to constant scrutiny by parents and society. They judge the performance of the teacher, the learner and the effectiveness of the programs through the learners' grades and the results of assessment. We illustrated these interrelations regarded to assessment in the chart of Figure 1.

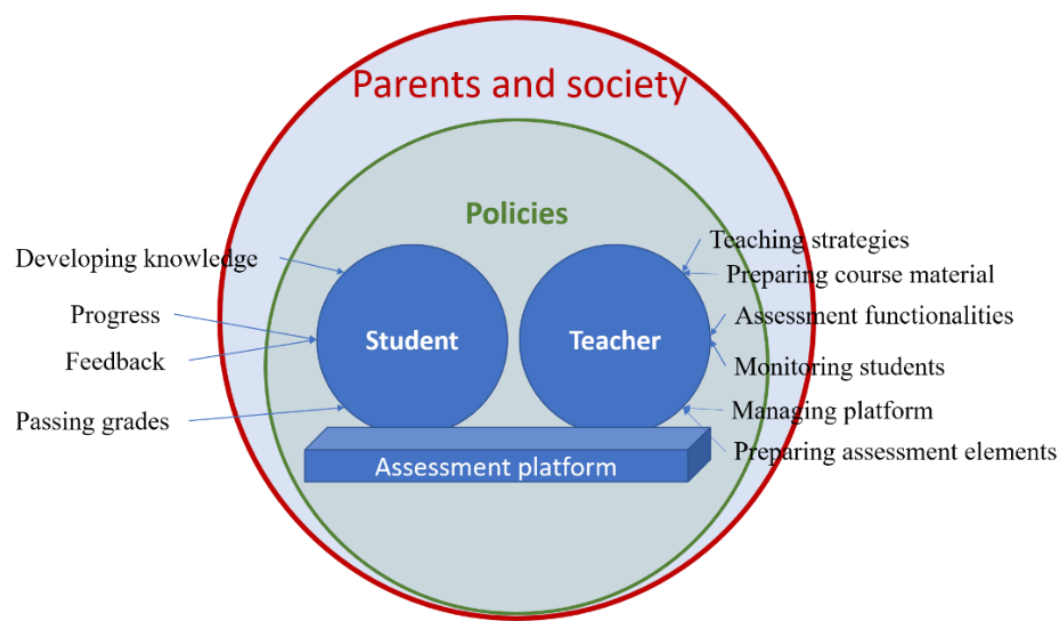

Figure 1: Interrelation between different parties regarding assessment

Implementation of assessment in educational practices presents significant challenges: first and foremost, the learner and the teacher should be highly engaged in the a ssessment operations. It should be fa miliar but compelling to both of them. Lack of this engagement have dra matic impact on the whole learning process.

Furthermore, in order to conduct an effective assessment, the teacher needs to take a number of decisions and measures. To cite just a few, he/she needs to:

- determine the objectives of the assessment and to determine which concepts and skills a re more important to emphasize on; Whether high-level or basic skills should be assessed,

- determine the form and the time of a ssessment

- determine the suited instrument to be used and which instrument is helpful into collecting information and giving clear evidence of learning.

- double-check the validity and the releva nce of the instrument to the established objectives,

- $\quad$ set criteria to a ssess each skill or knowledge 
- appraise or grade students according to their performances

- collect data and make analyses,

- give feedback and decide if this feedback will be provided collectively or individually according to the analyses of the outcomes

- $\quad$ take decision on the next learning steps and the teaching strategies.

- communicate the grades to the education authorities in the case of summative assessment.

Another significant challenge that should be mentioned is of the institutional instructions. Being rather rigid or not flexible enough to let teacher to take momentous decisions upon some assessment activities and to allow a free choice of instruments or means to assess the learning.

All the opera tions mentioned above a re almost always carried out by the teachers in their classical cla ssrooms and they are undoubtedly facing all or parts of the challenges cited above.

However, it turned out that these challenges exacerbated with the COVID-19 aftermath (Cavus, Mohammed, and Yakubu 2021; Hu et al. 2021). More significant challenges, in the whole learning/teaching process, were experienced by teachers, students and parents during the COVID-19 outbreak circumstances (Mishra, Gupta, and Shree 2020; Raza et al.2021). The assessment process was deeply impacted. During the pandemic, the lockdown was established and forced the schools to close. Distance teaching/learning was then the only alternative to maintain learning continuity. Teachers and students had to move from usualclassrooms monitored by teachers to virtual classes with self-paced learning mode. Teachers and students were facing new environment that has its specific rules and tools.

\section{Learning management systems (LMSs)}

LMSs are among the tools commonly known to provide a platform for distance teaching/learning. They create an online environment specifically dedicated to teaching and learning (Bradley 2021; Oliveira, Cunha, and Nakayama 2016).

LMSs are defined as web-based learning technologies. They are software applications intended for the creation, management and delivery of courses and material courses. LMSs allow the management of the learning process by enabling the teacher to monitor the students and their activities and to track their work and their progress. Several LMSs are a vailable and can be integrated by teachers in the different phases of teaching process. We can distinguish three types of LMSs: learning skills tools, communication tools and productivity tools.

Each LMS has a number of features that make it suitable for a particular learning situation. So, the choice must be made carefully to get the maximum benefit from a LMS and achieve the desired goals. It is noteworthy that this choice is also influenced by the knowledge and the skills of the teacher, the conditions and the infrastructure provided to the teacher (Ghilay 2019). 
During the COVID-19 pandemic, the situation was very critical since, nationwide, no school was adopting an LMS in-class courses. No training either was delivered to the teachers.

Without any preparedness or guidance, teachers had to face the situation and to make a choice on the platform they would use to deliver their courses during the lock-down.

In this work we intend to shed light on the difficulties and challenges encountered in distance learning during the COVID-19 era, especially those related to assessment, as identified by pre-service teachers.

\section{Method}

In this work, 23 teacher trainees were surveyed upon their distance learning experience during the COVID-19 lockdown. A questionnaire was administered to the trainees and round table discussion wa s also organized to collect their opinions and thoughts. The questionnaire had close and open-end questions.

Usually, during their training course, the trainees have to prepare a teaching session for students in one of the public schools. After that, a session is organized in the center to reflect on the practices of the trainees and to draw essential conclusions on which improvements can be made to their professional practices. However, the circumstances of the lock-down prevented this regular procedure and we have opted for the micro teaching. A trainee conducted a teaching session while the other trainees were playing the learners' role and they had to observe, review and analyze their colleague's practices. Participating in this micro-teaching, they have as well the opportunity to analyze the platform used to support the learning as teachers and as learners.

At first, the trainees picked liberally the platforms to use in their teaching experience. These platforms are summarized in Table 1 along with the number of trainees that used it.

Table 1: Platforms picked by the trainees in distance teaching-learning experience

\begin{tabular}{ll}
\hline Platform chosen & Number of trainees \\
\hline Discord & 1 \\
Google classroom & 13 \\
Google meet & 1 \\
Ms teams & 1 \\
WhatsApp & 6 \\
Drag'n survey & 1 \\
\hline
\end{tabular}

A variety of platforms were used by the trainees to conduct their teaching sessions. However, we can notice that almost all the trainees opted for free online tools. The trainees used educational tools largely a vailable and known 
by students and in-service teachers. Actually, they lack extensive knowledge of LMS. They asserted that it was difficult to handle. Although it has numerous features, they were unable to master the basics of most of LMS software in a harsh and very limited time. As displayed in table 1, these tools are as follows:

$>$ Discord: A VoIP platform; it has many features that the trainees exploited in distance teaching. Discord was essentially developed for gaming purpose. However, after many updates it becomes useful for general purposes. In fact, it is a group chat software essentially focused on communication. Members are grouped into a collection of channels called servers. These channels allow instant messaging, voice and video conversations, file sharing and instant streaming. Video calls and screen sharing are possible with up to 50 people. Access to a channelcan be customized to limit access from some users.

$>$ WhatsApp: A an instant messaging application. It allows file and multimedia sharing. It is principally dedicated to communication via text, voice and video calls (with up to 5 people simultaneously). The user can create an individual account or groups. Within these chat environments, users can share information, text files and multimedia resources.

$>$ Google classroom: A platform developed by Google. The teacher can create a class to which he/she invites his/her students using a unique code. The teacher can share announcements, course ressources, multimedia files throughout the class stream. The students can reply to these posts creating a communication environment. The teacher may also send documents to the students by e-mail. 13 trainees chose this platform.

> Microsoft Teams: A proprietary communication tool developed by Microsoft. During the COVId-19 pandemic, Ms Teams was used massively for educational purposes. It allows to set up individual accounts or groups of individuals (called teams). Within the teams, the teacher can set up channels to communicate with students, either in a private way or in group conversation. Ms Teams allows you to communicate with your team via text, voice or video meetings. It allows you also to create and send assignments to individual students or to a group of students.

$>$ Google Meet: A video conferencing application developed by Google. It allows direct commu nication between people (up to 25 at the time of the study) and screen sharing. There is also a chat area where users can communicate via text-messaging.

$>$ Drag'n survey: An online survey tool which has a free version. It allows the teacher to create a questionnaire that he/she can distribute online or integrate in his/her website. The teacher can choose from several types of questions (Yes/No questions, Quizzes, MCQ, drop-down, open questions, ...). It allows also to insert images. The teachercan also choose to use available templates. The teacherhas the possibility to score questions. It generates a report of the respondents' answers that the tea cher can upload in many formats.

\section{Results}

The trainees were asked to determine features they see relevant and $m$ aking strength of the platforms. The features are: 
- Messaging teacher-student

- Audio interaction

- Video interaction

- Feedback on students' work

- Interactive assessment

The results are reported in Figure 2.

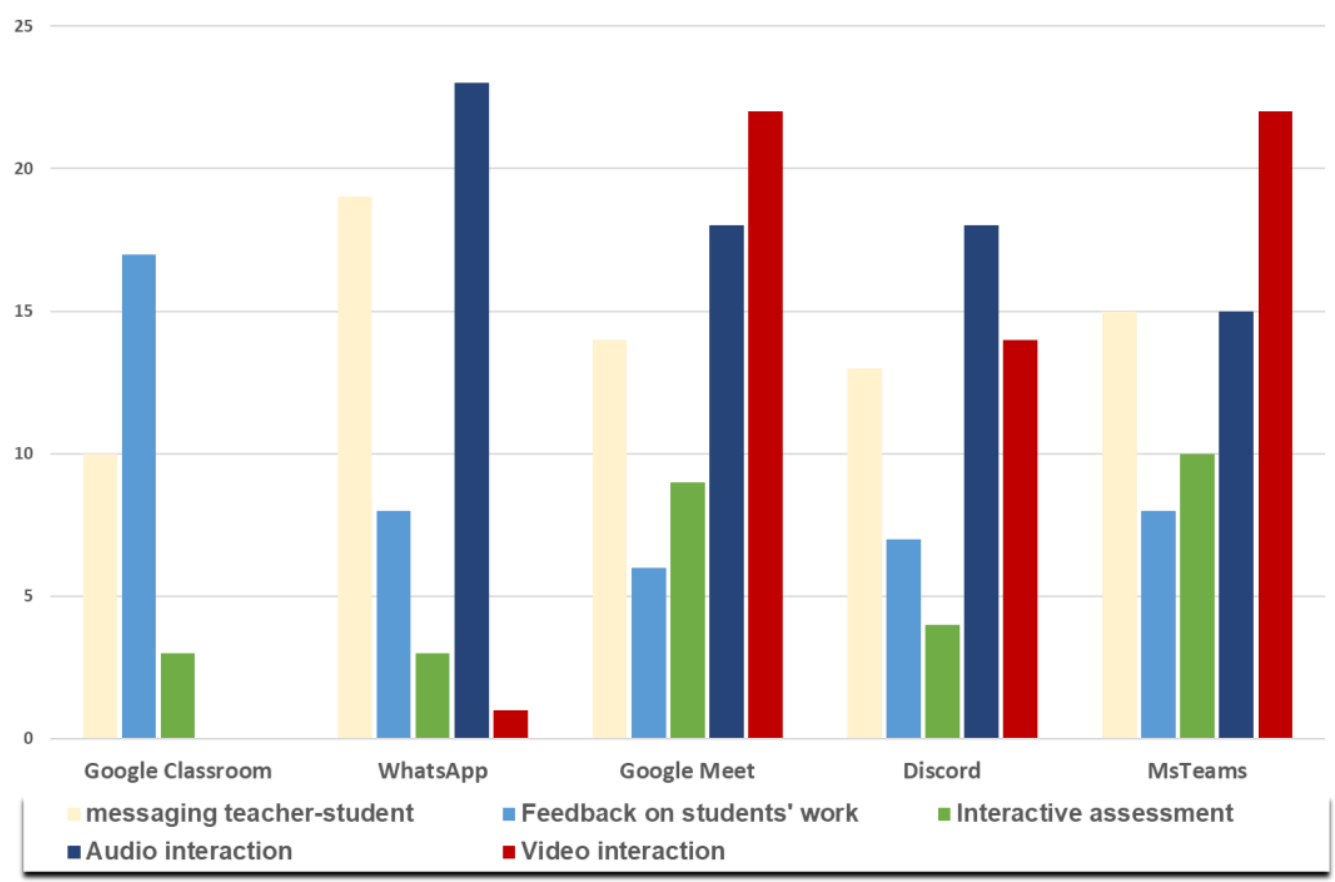

Figure 2: Strengths of the platforms as seen by the trainees

From Figure 2 we can infer that audio and video interaction features are the main factors deemed relevant for an on-line platform. Especially for WhatsApp, MsTeams and Discord. Messa ging student-teacher comes second.

At the end of each teaching session, each trainee expressed his/her contentment. They had to specify his/her degree of satisfaction with the platform they used. They had then to choose from 5 answer options. The results are gathered in Table 2. 
Table 2: Satisfaction of trainees over using the platforms

\begin{tabular}{|c|c|c|c|c|c|c|}
\hline $\begin{array}{l}\text { Platforms/degree of } \\
\text { satisfaction }\end{array}$ & $\begin{array}{l}\text { Google } \\
\text { classroom }\end{array}$ & WhatsApp & $\begin{array}{l}\text { Google } \\
\text { meet }\end{array}$ & Discord & $\begin{array}{l}\text { Drag'n } \\
\text { survey }\end{array}$ & MsTeams \\
\hline Not at all satisfied & 2 & 1 & & & & \\
\hline Not satisfied & 6 & 3 & & 1 & & \\
\hline Satisfied & 4 & 2 & & & & 1 \\
\hline Very satisfied & 1 & & 1 & & 1 & \\
\hline Total & 13 & 6 & 1 & 1 & 1 & 1 \\
\hline
\end{tabular}

From the results displayed in Table 2, we can see that the trainees who used Drag'n survey and MsTeams derived satisfaction from the platforms. 8 trainees out of 13 that used Google classroom were not satisfied with their choice ( 2 were not at all satisfied). Out of 6 trainees that used the WhatsApp as teaching platform 4 were not satisfied (one was not satisfied at all).

The trainee who used MsTeams asserted that she was satisfied with the platform. "I took advantage of the video conference to maintain a dynamic interaction and to share my screen with students. I could manage assignments setting up scored quizzes to promote and to track students' progress. The students handed in the assignment on a scheduled time and I provided my feedback after reviewing their work"

By providing the Visio conference feature, Discord and Google meet allow face-to-face conversations. They provide an interactive and collaborative space for students and teachers. They allow easy course materials and screen sharing with students, which offer a user-friendly environment where students and teachers feel comfortable as in a regular classroom. The teacher can use e-mail in the case of Google meet to deliver course materials to the students. These platforms enable constant interaction with the students, either by high quality audio calls or video meetings. The video conversa tion facilitated the formative a ssessment. "To assess the students' understanding, I was asking questions and getting instant answers from the students. I was receiving and answering the students' questions as well. I faced an organizational problem. I couldn't maintain order and determine who was asking to participate, the raise hand function was absent" asserted the trainee who used google meet.

The trainee who used Drag'n survey was satisfied with her performance. She used Drag'n survey to conduct a summative assessment session. "I was able to use different kinds of questions (False/true questions, open -ended questions, multiple-choice questions). I was able to insert images and ask students to give comments. The automatic interactive feature gave the students the opportunity to get immediate feedback".

About $62 \%$ of the trainees that used Google Classroom for their teaching session were not satisfied. In their experience, the lesson content was shared with the students via the platform or via e-mail. In some cases, the lesson content was grained and was delivered by portions via messages posted by the teacher in the class Stream. 
The conversation between teacher and students was held using text messages. The students could discuss, write comments, ask questions and the teachers were reacting by writing back in the same Stream.

"What I appreciate in Classroom is the assignment feature it provides. I could create and dispense assignments to students at the end of the teaching session. The students had to accomplish the work and to return it via the platform on the due date and time I already set up. Using the platform, I could review their work and grade it. I could also give feedback to each student" asserted a trainee. However, there was a broad consensus among the trainees on the fact that the process was very slow; they had to wait very long for the reaction of students to their posts.

The trainees who used WhatsApp encountered serious problems in prompting the student's engagement and getting their attention. They didn't have clear evidence of their assistance to the lesson. The possible strategy was to record a piece of the lecture and to send it via the platform. In many instances, a document was shared with the students. They read it on their own and if they had a mbiguities, they could ask questions via voice or text messages. The lesson session required longer time.

The trainees were also asked about their preferences of the mode of assessment (To share a document or use of interactive platform). The results, as depicted in Figure 2, show a strong preference for the interactive assessment (65\% of the trainees) rather than the shared documents. Platforms incorporating interactive assessment are highly desirable and recommended.

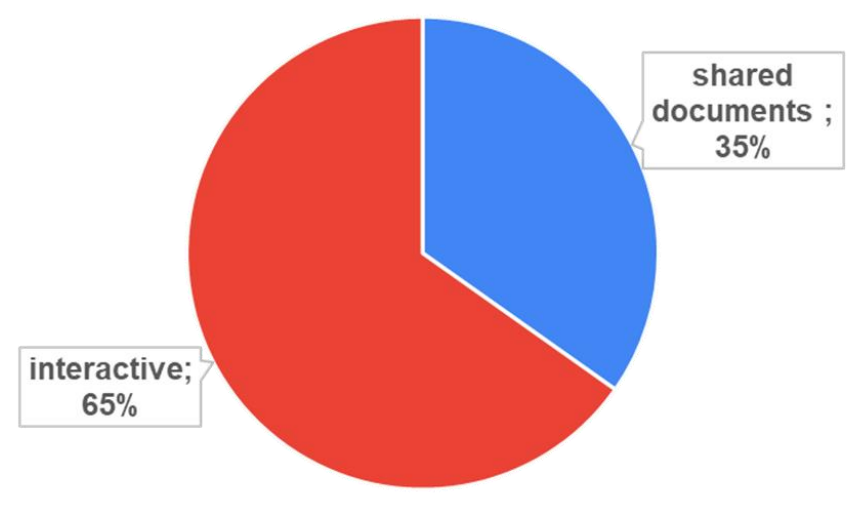

Figure 2: the preferences of the trainees for mode of assessment

\section{Discussion and analysis}

The trainees who used discord, Google meet or Ms Teams adopted the questioning and the discussion as form of assessment. The questioning was used to assess the students' understanding rather than the student's thinking or the student's skills. Although this form of assessment was embedded in the learning activities and it ensured a formative assessment, it would be insufficient in the case of performance assessment (Overton 2012) where 
students' skills are the main target of the assessment. The questioning ensures the engagement of students and enhances active interaction between the students and the teacher and it leads to a successful co-regulation of learning. However, it is difficult to assess high-order thinking skills. It is important to keep in mind that questioning remains a critical form of assessment. Many teachers fail to formulate high qua lity questions that give evidence on the students' understanding and can really give clues to guide the teacher to the way he/she can improve and develop his/her teaching strategies.

\section{Challenges to teachers}

In addition to the challenge assessment usually present, many others were experienced by the teachers in the era of COVID-19. Teachers needed LMS or online tools to accomplish distance learning and to maintain learning continuity. They needed to a ssess students' strengths, weaknesses, and needs and to gather information to plan other activities or change their teaching strategies.

It is inarguably that assessment is an integral part of any learning process and they can't be separated if we aim for high-quality learning. Many tools used by the trainees in this work and by many otherin-service teachers, such as WhatsApp, Google Classroom, didn't facilitate this integration. There was a rigidity in the platform that made the learning-teaching process almost asynchronous. Teachers used time in waiting the students' response that could be more profitably spent on other activities. This required drastic reorganization of classroom operations. Teachers had so to rethink their teaching strategies and to adapt them to these unusual circumstances. Even though these conditions created frustration to many teachers.

This flexibility was provided by video conversation in Google meet, discord and MsTeams and allowed more interaction between teachers and students. It let more room to formative assessment. Questioning was used by teachers to assess the student's understanding during the course of the interventions. It was clearly emphasized in the literature that the assessment, especially in its formative form, is highly effective when it is implemented into daily classroom practices. So, the teacher is able to identify immediately the errors in the students' performances, to determine the specific learning difficulties and to intervene promptly by further regulation (Bloom 1984; Setiawan, 2021; 2020; Wiliam 2011). The immediacy in assessing and intervention improves the student's learning and boosts the teachers' professional development by providing immediate feedback on the whole process outcomes. Providing feedback on the students' work, either after an instant or asynchronous assessment, is an important factor in students motivation and engagement and it is essential to achieve assessment functions. Many tools used by the trainees provide functiona lities that allow giving feedback and that made their strengths as stated by the trainees (Figure 1). In addition to the communication established between the teacher and the student via the canal of the feedback, it encompasses a large number of valuable instructions that help regulating and refining the learning. More, individual feedback enhances motivation of students. For distance learning, this characteristic is very required and increases interest in LMS and other tools providing this feature. Both students and teachers are in dire need of this feature since it triggers interest and motivation of students. Actually, interest is tightly related to dynamic interaction (Hidi 2001) provided by online tools if they are well mastered. Dewey (Dewey 1913) stated that if the student shows interest he would work hard and strive to learn what he is interested in and 
achieve proficiency. He would develop positive attitudes such as intrinsic motivation, perseveran ce and mastery goals. Choosing the right LMS or online tool that achieve these goals places a heavy burden on the teachers. Sending material courses via an online tool helped neither in creating interaction nor in stimulating interest of students. Some LMS permit automatic feedback supporting the self-assessment, the self-regulation of the student learning and hence fostering the electronic interaction. This enhances the effectiveness of the platform. Lack of assessment and feedback features reduces the accuracy and the efficiency of distance learning. As alternative to these features, the trainees that used WhatsApp used Google forms or other quizzes platforms.

In addition to the challenge assessment usually present, many others were experienced by the tea chers in the era of COVID-19 (Setiawan, 2020). Teachers needed LMS or online tools to accomplish distance learning and to maintain learning continuity. They needed to assess students' strengths, weaknesses, and needs and to gather information to plan other activities or change their teaching strategies.

It is inarguably that assessment is an integral part of any learning process and they can't be separated if we aim for high-quality learning. Many tools used by the trainees in this work and by many other in-service teachers, such as WhatsApp, Google Classroom, didn't facilitate this integration. There was a rigidity in the platform that made the learning-teaching process almost asynchronous. Teachers used time in waiting the students' response that could be more profitably spent on other activities. This required drastic reorganization of classroom operations. Teachers had so to rethink their tea ching strategies and to adapt them to these unusual circumstances. Even though these conditions created frustration to many teachers.

This flexibility was provided by video conversation in Google meet, discord and MsTeams and allowed more interaction between teachers and students. It let more room to formative assessment. Questioning was used by teachers to assess the student's understanding during the course of the interventions. It was clearly emphasized in the literature that the assessment, especially in its formative form, is highly effective when it is implemented into daily classroom practices. So, the teacher is able to identify immediately the errors in the students' performances, to determine the specific learning difficulties and to intervene promptly by further regulation (Bloom 1984; Wiliam 2011). The immediacy in assessing and intervention improves the student's learning and boosts the teachers' professional development by providing immediate feedback on the whole process outcomes. Providing feedback on the students' work, either after an instant or asynchronous assessment, is an importa nt factor in students motivation and engagement and it is essential to achieve assessment functions. Many tools used by the trainees provide functionalities that allow giving feedback and that made their strengths as stated by the trainees (Figure 1). In addition to the communication established between the teacher and the student via the canal of the feedback, it encompasses a large number of valuable instructions that help regulating and refining the learning. More, individual feedback enhances motivation of students. For distance learning, this characteristic is very required and increases interest in LMS and other tools providing this feature. Both students and teachers are in dire need of this feature since it triggers interest and motivation of students. Actually, interest is tightly related to dynamic interaction (Hidi 2001) provided by online tools if they are well mastered. Dewey (Dewey 1913) stated that if the student shows interest he would work hard and strive to learn what he is interested in and achieve proficiency. He would develop positive attitudes such as intrinsic motivation, perseverance and mastery goals. 
Choosing the right LMS or online tool that achieve these goals places a heavy burden on the teachers. Sending material courses via an online tool helped neither in creating interaction nor in stimulating interest of students. Some LMS permit automatic feedback supporting the self-a ssessment, the self-regulation of the student learning and hence fostering the electronic interaction. This enhances the effectiveness of the platform. Lack of assessment and feedback features reduces the accuracy and the efficiency of distance learning. As alternative to these features, the trainees that used WhatsApp used Google forms or other quizzes platforms.

\section{Challenges to students and their involvement in assessment}

Students' engagement in the assessment depends firmly on the intere st they prove to the whole process. The more they gain confidence in the process, the more they invest effort in assignments and try to improve their performances (Hidi 2001). Platforms that fail in stimulating students' engagement lose attraction. During the COVID-19 era, Students' engagement was at its lowest level. The students worked from home, their comfortable zone and where many distraction sources were present: TV, all family members, ... Students were required to make a big effort to focus and to get engaged in learning activities.

Discord platform was good in creating interactive environment, but it adds more distractions to students seeking concentration and focus.

Self-assessment is another assessment form that has a positive impact on learning and helps to foster the metacognitive capabilities of students. It can be viewed as an unguided reflection on the performance. The self assessment inquires intense engagement from the students and accelerates considerably the learning mastery. As Yan and Brown (Yan and Brown 2016) stated "Self-assessment requires the initiation of learners into reflective practice". However, this was quasi absent during the COVID-19 pandemic. Almost in all instances, sharp focus was placed on delivering the course materialand little on the assessment and its role in assisting students to learn. There has been no interest in the self-assessment.

One of the biggest problems encountered by students during the COVID-19 pandemic is the lack of resources to use in distance learning. The majority of the students have no computer and no smartphone. Attending classes was difficult if not impossible. At the best of times, some relatively privileged families could provide their children with only one device. But one device should serve for numerous children either by turn, or by priority. Receiving a piece of document from the teacher usually turned to be better for these students. So, they could learn at their own speed.

Additionally, automatic assessments that allow automatic feedback requires students to be connected to the internet. During the aftermath, the speed of the internet was very low and the service was very bad. Getting automatic assessments became a hell.

\section{Conclusions}


Generally, the implementation of assessment in learning process is very complex and poses many challenges. In the COVID-19, the situation was exacerbated and teachers faced additionalchallenges.

From the present study, we can say that there are sound rea sons for the failure of distance learning/teaching during the COVID-19 era. We can point to many issues impacting the implementation of assessment in learning practices during the lockdown:

- The competencies of teachers in terms of assessment role and their awareness about the assessment functionalities. One major issue in the success implementation of assessment in the learning process is largely related to the teacher's representation of a ssessment role and how to implement assessment activities and feedback in practice.

- The competencies of teachers in terms of distance learning strategies. What is needed are the skills to use online resources and to take the largest benefit of it.

- The competencies of teachers regarding the usage of ICT and the LMS and their capacity to make the right choice.

- Teachers shouldn't shoulder the burden alone, the educational authorities share the responsibility. The availability of solid infrastructure supporting the distance learning and providing a broad selection of online structures and platforms allowing a wide range of choices.

Therefore, there is a big need to establish a strategic educational plan for strengthening the teachers' skills in adopting best assessment practices, and underta ke steps to reinforce infrastructure necessary to conduct a highquality distance-learning. It is compulsory to anticipa te urgency and to adopt training programs to support teachers in their professionaldevelopment in assessment and the efficient use of the right LMS as priority policy initiative.

\section{References}

Bloom, Benjamin. 1984. "The Search for Methods of Instruction as Effective as One-to-One Tutoring." Educational Leadership 41(8):4-17.

Bradley, V. M; 2021. “Learning Management System (LMS) Use with Online Instruction.” International Journal of Technology in Education 4(1):68-92.

Cavus, Nadire, Yakubu Bala Mohammed, and Mohammed Nasiru Yakubu. 2021. "Determinants of Learning Management Systems during COVID-19 Pandemic for Sustainable Education." Sustainability 13(9):5189. doi: 10.3390/su13095189.

Dewey, J. 1913. Interest and Effort in Education. Riverside Press. Boston: Riverside Press.

Ghilay, Yaron. 2019. "Effectiveness of Learning Mana gement Systems in Higher Education: Views of Lecturers with Different Levels of Activity in LMSs.” 3(2):29-50.

Hidi, S. 2001. "Interest, Psychology Of.” Pp. 7712-15 in International Encyclopedia of the Social \& Behavioral Sciences, edited by N. J. Smelser and P. B. Baltes. Oxford: Pergamon. 
Hu, Ben, Hua Guo, Peng Zhou, and Zheng-Li Shi. 2021. "Characteristics of SARS-CoV-2 and COVID-19." Nature Reviews Microbiology 19(3):141-54. doi: 10.1038/s41579-020-00459-7.

Mishra, Lokanath, Tushar Gupta, and Abha Shree. 2020. "Online Teaching-Learning in Higher Education during Lockdown Period of COVID-19 Pandemic." International Journal of Educational Research Open 1:100012. doi: 10.1016/j.ijedro.2020.100012.

Oliveira, Paulo Cristiano de, Cristiano José C. de A. Cunha, and Marina Keiko Nakayama. 2016. "Learning Management Systems (LMS) and e-Learning Management: An Integrative Review and Research Agenda." Journal of Information Systems and Technology Management 13(2):157-80. doi: 10.4301/S1807-17752016000200001.

Overton, Terry. 2012. Assessing Learners with Special Needs, An Applied Approach. Seventh edition. New Jersey: Pearson.

Raza, Syed A., Wasim Qazi, Komal Akram Khan, and Javeria Salam.2021. "Social Isolation and Acceptance of the Learning Management System (LMS) in the Time of COVID-19 Pandemic: An Expansion of the UTAUT Model." Journal of Educational Computing Research 59(2):183-208. doi: 10.1177/0735633120960421.

Setiawan, Adib Rifqi. 2021. "Six Ma in Principles for Quality Learning Based on Ta'līm al-Muta'allim Țorīq alTa'allum.” Religio Education 1(1):57-75.

Setiawan, Adib Rifqi. 2020. "Motivasi dan Hasil Belajar dalam Pembelajaran Adaptif Fisika menggunakan Naḍom Mabādī "Asyroh.” WaPFi (Wahana Pendidikan Fisika) 15(2):132-146. doi: 10.17509/wapfi.v5i2.14566.

Wiliam, Dylan. 2011. "What Is Assessment for Learning?” Studies in Educational Evaluation 37(1):3-14. doi: 10.1016/j.stueduc.2011.03.001.

Yan, Zi, and Gavin T. L. Brown. 2016. "A Cyclical Self-Assessment Process: Towards a Model of How Students Engage in Self-Assessment." Assessment \& Evaluation in Higher Education 1-16. 